\title{
Combinación de Inmunidad a los Virus $X$ e $Y$ de la Papa y Resistencia a P. infestans en Clones de Papa
}

José Luis Zapata Pareja, ${ }^{1}$ Enrique N. Fernández-Northcote ${ }^{2}$

\begin{abstract}
Resumen
Ciento doce progenies derivadas de cruzamientos de clones inmunes a PVX y PVY usados como progenitores femeninos, y clones resistentes a $P$. infestans, como padres, fueron tamizadas para inmunidad a virus bajo condiciones de invernadero en Tibaitatá y bajo un cobertor rústico de malla, y de tinglado en "La Selva". Luego, la planta madre sobreviviente y un esqueje de cada genotipo se evaluaron en el campo, ó se tamizaron en invernadero o tinglado, respectivamente, para resistencia a $P$. infestans. En el invernadero y en el cobertor rústico se usó una raza compleja del hongo, mientras que en el campo, los clones estuvieron expuestos a la población natural de $P$. infestans. El tamizado para inmunidad a virus fue más adecuado en el invernadero de Tibaitatá, ya que el porcentaje de plántulas asintomáticas estuvo más cerca de lo esperado. Un porcentaje más bajo de clones fue resistente al tizón tardío en el cobertor rústico, indicando que en este ambiente el descarte fue más severo; sin embargo, se obtuvo un alto número de genotipos que no fueron resistentes bajo condiciones de campo. Sólo 21 y $28 \%$ de los genotipos resistentes en el invernadero y cobertor rústico, respectivamente, fueron también resistentes en condiciones de campo en "La Selva", y con adaptación agronómica. No se detectaron padres con habilidad para transmitir resistencia a $P$. infestans en todos los ambientes probados.
\end{abstract}

Palabras claves adicionales: $\quad$ tizón tardío, Phytophthora infestans, resistencia, inmunidad, habilidad combinatoria.

Aceptado para publicación: marzo 1997.

1 Ing. Agr., Mg. Sc. Regional 4, AA :100 Rionegro (Ant.), Colombia Ing. Agr., Ph.D. Virólogo Centro Internacional de la Papa. Apartado Aéreo 1558 Lima 12, Perú. 


\title{
Combination of Immunity to Viruses $\mathrm{X}$ and $\mathrm{Y}$ of Potato and Resistance to $P$. infestans in Potato Clones
}

\begin{abstract}
Summary
One hundred and twelve progenies derived from crosses using clones immune to PVX and PVY as their female parent and clones resistant to $P$. infestans as male parents were screened for immunity to viruses under greenhouse conditions in Tibaitatá and screenhouse in La Selva. The surviving mother plant and a stem cutting from each genotype were evaluated in the field or screened for resistance to $P$. infestans in the greenhouse or screenhouse respectively. In the greenhouse and the screenhouse a complex strain of the fungus was used, while under field conditions the clones were exposed to a natural population of $P$. infestans. Screening for virus immunity was more efficient in the greenhouse in Tibaitatá since the percentage of asymptomatic plants was closer to the expected value.
\end{abstract}

In the screenhouse a lower percentage of clones were found to be resistant to late blight, indicating that under these conditions thinning was more severe. Even so, a large number of genotypes were not resistant under field conditions. Only $21 \%$ and $28 \%$ of the genotypes resistant in the greenhouse and screenhouse respectively, were also resistant under field conditions in La Selva and showed agronomic adaptation. No parents with the ability to transmit resistance to $P$. infestans under all the conditions described were found.

Additional index words: late blight, Phytophthora infestans, resistance, immunity, combining ability.

\section{Introducción}

A nivel mundial los virus $X(P V X)$ e $Y(P V Y)$ de la papa son dos de los más importantes en el cultivo de la papa, debido a su fácil diseminación, a que pueden disminuir el rendimiento hasta en un 80\% (Barrera, 1987; Bokx, 1980; y Fernández-Northcote, 1983) y a que son dos de los principales virus involucrados en la degeneración de la papa. 
La resistencia a estos virus es la mejor alternativa para su control reduciendo los riesgos que corre el pequeño agricultor al utilizar tubérculos-semillas infectados en su próxima siembra (Centro Internacional de la Papa, 1979; García,1989),

El tizón tardío causado por el hongo Phytophthora infestans (Mont) de Bary, también constituye otro de los grandes problemas fitopatológicos en casi todas las áreas del mundo donde se cultiva papa (Henfling, 1987; Hooker, 1980). El tizón o rancha o gota, es probablemente la enfermedad fungosa más seria de la papa, ya que en condiciones favorables para su desarrollo puede devastar un campo en pocos días.

Por las razones antes expuestas, se vio la necesidad de desarrollar una estrategia de mejoramiento de poblaciones de papa, orientada a combinar inmunidad a los virus antes mencionados, con la resistencia o tolerancia al tizón tardío.

Los objetivos principales fueron: Identificar progenies inmunes a los virus PVX y PVY con resistencia a $P$. infestans, correlacionar la resistencia al tizón tardío obtenida en invernadero con la obtenida en el campo, y hallar la habilidad combinatoria general de los padres para resistencia al hongo.

La papa es hospedante natural de numerosos virus, entre los cuales dos de los más importantes son el PVX y PVY, causantes de síntomas severos.

Según Bokx y Hooker (1980), el PVX es de distribución mundial, presentándose en todas las zonas dedicadas al cultivo de la papa. Durante mucho tiempo se le consideró inofensivo; sin embargo, pruebas cuidadosas demostraron una disminución en la cosecha hasta del 10\%, que varía de acuerdo a las razas del virus y a la variedad de papa.

Hooker (1980) y Muñoz (1975) afirman que el mejoramiento para PVX está basado en tres tipos de resistencia: resistencia a la infección conferida por genes menores, hipersensibilidad e inmunidad conferida por el gen Ry, detectado por Stelzner en S. stoloniferum; también se ha detectado en $S$. hougasii, y $S$. andigena. Actualmente algunos programas de mejoramiento europeos tienen variedades comerciales con este gen. Fernández-Northcote (comunicación personal) ha detectado algunos clones que han demostrado inmunidad al PVX y PVY en condiciones de invernadero y campo. El programa de mejoramiento para resistencia a PVX y PVY del CIP utiliza este nivel de resistencia.

El mecanismo de control del tizón tardío está basado en dos tipos: La resistencia específica de raza y la resistencia general (7). 
La resistencia específica solamente es efectiva contra ciertas razas del hongo. Es controlada por genes dominantes $\mathrm{R}$, relativamente fáciles de heredar. Es llamada también resistencia de genes R, resistencia por genes mayores y resistencia vertical. Estos genes $\mathrm{R}$ están estrechamente relacionados con los genes de virulencia del hongo. Producen una reacción de hipersensibilidad en la planta. Actualmente se conocen 12 genes $R$ y $12 \mathrm{r}$ de virulencia del hongo para un total de $2^{12}=4,096$ razas posibles.

La resistencia general, es llamada también resistencia de campo, resistencia horizontal o resistencia de genes menores. Es de carácter cuantitativo, controlada por muchos genes, cada uno de los cuales puede contribuir en mayor o menor grado a la resistencia. Esta resistencia ha sido observada en S. andigena, S. bulbocastanum y S. stoloniferum.

Hasta el momento no se ha reportado un estudio en el que se intente combinar la inmunidad a los virus PVX y PVY con resistencia al tizón tardío tanto en condiciones de campo como de invernadero.

\section{Materiales y Métodos}

El presente trabajo se inició determinando la inmunidad a los virus PVX y PVY de los clones que posteriormente se usaron como padres. Para esto, los clones fueron probados serológicamente con la técnica de ELISA para el virus $\mathrm{S}$ de la papa (PVS) y el virus del enrollamiento de la hoja de papa (PLRV), conforme a la metodología seguida por el CIP, todas las plantas positivas a dichos virus fueron eliminadas.

Luego las plantas sanas se probaron para inmunidad a PVY y PVX de la forma siguiente: Tres plantas fueron injertadas con yemas de Nicotiana occidentalis infectadas con un aislamiento de $\mathrm{PVY}^{\circ}$, tres plantas se inocularon mecánicamente con savia de la misma indicadora y la misma variante del virus, y una planta se dejó como control. Los clones asintomáticos se probaron serológicamente (ELISA) para PVY y los sanos fueron retroinoculados en plántulas de $N$. occidentalis. 
Para el caso de PVX, se utilizó la misma metodología, pero utilizando savia de $N$. glutinosa infectada con $\mathrm{PVX}_{\mathrm{cp}}$ para inoculación mecánica, yemas de la variedad Rosita infectadas con la misma variante para el injerto y retroinoculación en plántulas de $N$. glutinosa.

Posteriormente, 112 progenies de cruzamientos de clones inmunes por resistentes fueron tamizadas para los virus PVX y PVY bajo condiciones de invernadero en el CNI Tibaitatá y de tinglado en el Cl La Selva del Instituto Colombiano Agropecuario (ICA). Se siguió el método de inoculación masal con pistola de pintor. Para ello se tomaron hojas tiernas de $N$. occidentalis infectadas con el aislamiento colombiano $P V Y^{N}$ y hojas $N$. glutinosa infectadas con otro aislamiento colombiano de PVX perteneciente al serogrupo IV serotipo $\mathrm{PVX}^{\circ}$. Las plántulas fueron asperjadas con el inoculo localizando la pistola a una distancia de 1.5 a $2.0 \mathrm{~cm}$ de ellas y aplicando la suspensión a cada plántula con una presión de $30 \mathrm{lb} / \mathrm{plg}^{2}$. Después las plántulas se incubaron a $17^{\circ} \mathrm{C}$ aproximadamente durante $24 \mathrm{~h}$.

De cada plántula asintomática se sacó un esqueje. Tanto el esqueje como su planta madre, fueron evaluados en invernadero o tinglado, o campo, respectivamente, para resistencia al tizón tardío. Bajo condiciones de invernadero y tinglado se usó una suspensión de 3.500 esporangios $/ \mathrm{mL}$ de una raza compleja del hongo con los siguientes genes de virulencia: 1, 2, 3, 4, $6,7,8,10$ y 11 , mientras que en el campo, los clones estuvieron expuestos a la población natural del hongo. Durante tres días se mantuvo la humedad relativa por encima del $80 \%$ dentro del invernadero-tinglado para favorecer el desarrollo del hongo. Seis días después de la inoculación se seleccionaron las plantas resistentes (con manchas pequeñas del hongo) y las inmunes; las susceptibles fueron descartadas. En el campo la incidencia del tizón tardío se evaluó cada ocho días, durante cuatro semanas, en época de incidencia natural del patógeno, empleando la escala propuesta por el CIP.

Para el desarrollo de este trabajo se consideraron 2 planes: En el plan A se tamizó para inmunidad a PVX y PVY y resistencia a $P$. infestans en invernadero de Tibaitatá y la evaluación para resistencia a $P$. infestans se realizó en el campo de La Selva. En el plan B el tamizado para inmunidad a los virus y para resistencia a $P$. infestans en tinglado así como la evaluación de resistencia a $P$. infestans en el campo se realizaron en La Selva. Se hicieron dos evaluaciones de campo para resistencia a $P$. infestans en dos años consecutivos. 
Para calcular la habilidad combinatoria general (hcg), se siguió el método desarrollado por Singh y Chaudhary (1977) para el diseño "Línea x Probador", según las siguientes fórmulas:
a) $g p=$$$
\frac{\mathrm{xi} . .}{\mathrm{pr}}-\frac{\mathrm{x} . .}{\mathrm{plr}}
$$$$
\text { b) } g p=\frac{x i . .}{p r}-\frac{x . .}{p l r}
$$

en donde:

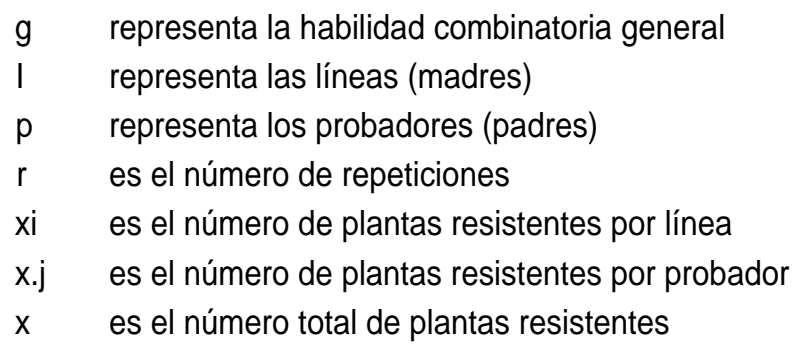

\section{Resultados y Discusión}

\section{Desarrollo del plan A}

De un total de 44,800 semillas sembradas se obtuvo un porcentaje de germinación del $91.83 \%$, el cual se considera alto, debido a la amplia variabilidad genética involucrada en el experimento.

Posteriormente, se hizo el primer tamizado de plántulas, para la mezcla de los virus PVX y PVY. Los síntomas más comunes fueron: necrosis de nervaduras, y mosaicos suaves y severos.

Con excepción de las combinaciones del probador I-1039 con todas las líneas, el resto de cruzamientos deben ser del tipo XxxxYyyy $x$ xxxxyyyy, que deberían dar un potencial del $25 \%$ de inmunes a PVX y PVY. Con excepción de la progenie 388422 que presentó $53.7 \%$ de plántulas asintomáticas, el promedio general fue del $20.34 \%$, muy similar a lo esperado. En la progenie 388422, el alto porcentaje se debe posiblemente a la presencia del LT-7 en la madre, el cual produce síntomas de hipersensibilidad cuando es inoculado con un aislamiento de $\mathrm{PVY}^{\circ}$ (Fernández-Northcote, comunicación personal). 
Las condiciones climáticas de Tibaitatá, en especial la temperatura dentro del invernadero, fueron apropiadas para el tamizado.

Referente al tamizado de esquejes para resistencia a $P$. infestans, en un total de 8,370 esquejes tamizados 1,427 (17.04\%) fueron resistentes. El rango de plantas resistentes por familia estuvo entre 0 y $45.6 \%$. El porcentaje promedio fue del $17.04 \%$, valor muy similar a los obtenidos por otros investigadores, en la misma localidad, siendo estos del $20 \%$ aproximadamente (informes anuales del Programa Papa, Colombia, datos no publicados).

Con excepción de la familia 388383 [(LT-8 x C83-119)2 x I1039] todas las familias completamente susceptibles al hongo, tienen como progenitores masculinos a Tollocan y 575049, los cuales son considerados resistentes en otros países bajo condiciones de campo. Al parecer Tollocan y 575049 tienen genes mayores, los cuales posiblemente son eliminados en el tamizado con la raza compleja; el resto de las progenies debe tener resistencia horizontal, o resistencia horizontal combinada con los genes $\mathrm{R}$ no compatibles con genes de virulencia en la raza del patógeno utilizado, o resistencia parcial conferida por los genes R2, R4, R10 y R11 y sus combinaciones (Turkensteen, 1989).

Los resultados obtenidos en la evaluación de la resistencia a $P$. infestans en el campo muestran un alto porcentaje de plantas resistentes. De 6,093 plántulas trasplantadas al campo, 1,116 (18.13\%) se comportaron como resistentes. En la cosecha fueron seleccionados 114 clones altamente resistentes al hongo y de buenas cualidades agronómicas, según los resultados obtenidos en la evaluación de esquejes bajo condiciones de invernadero (1,427 clones resistentes) y los 114 resistentes seleccionados bajo condiciones de campo, se encontró que 24 fueron comunes en las dos evaluaciones, lo que indica que posiblemente son los más resistentes. Los 114 clones fueron evaluados nuevamente en el campo, y seleccionados 36 de ellos, el resto fue eliminado principalmente por características agronómicas no deseables localmente. Los clones seleccionados fueron chequeados serológicamente (ELISA) para los virus PVX y PVY, obteniéndose reacción negativa a ambos virus en 27 (75\%) clones, 6 (16.6\%) fueron positivos al PVX, y 3 (8.3\%) positivos al PVY.

\section{Desarrollo del plan B}

De 44,000 semillas sembradas, se obtuvo un porcentaje de germinación del $85.15 \%$, mucho más bajo que el obtenido en el plan A, a pesar de que se usó el mismo sustrato. 
Se tamizaron 37,480 plántulas para los virus PVX y PVY, obteniéndose 14,495 (38.67\%) plántulas asintomáticas; este valor es muy superior al promedio esperado. Según los resultados obtenidos bajo condiciones de tinglado en La Selva, se aprecia un incremento considerable de plántulas asintomáticas por familia, de lo cual se puede inferir que las condiciones no favorecieron el tamizado, ya que se presentaron temperaturas promedio por encima de $25{ }^{\circ} \mathrm{C}$, las cuales tienden a enmascarar los síntomas virales (Hooker, 1980), permitiendo que se presenten escapes de material infectado, no detectado por sintomatología. Igual que en el Plan A, la progenie 388422 presentó el porcentaje más alto (74.4\%) de plántulas asintomáticas.

Referente al tamizado de esqueje para $P$. infestans dentro del tinglado, los resultados obtenidos muestran un comportamiento diferente al obtenido en el Plan A. De 14,495 esquejes tamizados, solamente 770 (5.31\%) fueron resistentes, comparados con $17.04 \%$ obtenidos en el Plan A. Ambos tamizados se hicieron con la misma raza del hongo y las mismas progenies, lo cual sugiere que los resultados del tamizado, dependen altamente de las condiciones ambientales. Antes de realizar el tamizado, bajo condiciones de tinglado, se presentó una epidemia fuerte con la población natural del hongo, la cual eliminó muchos genotipos susceptibles.

Para evaluar resistencia a $P$. infestans en el campo, solamente fueron probadas 5,322 plantas madres, de las que se obtuvieron 1,011 (18.90\%) clones resistentes, porcentaje muy similar obtenido en la misma localidad en el desarrollo del Plan A (18.13\%). Durante la cosecha, se seleccionaron 115 clones resistentes al hongo, asintomáticos a PVX y PVY, y con características agronómicas deseables.

Teniendo en cuenta los 770 clones resistentes bajo condiciones de tinglado y los 115 resistentes en el campo, se encontró que 32 clones fueron comunes en ambas evaluaciones, lo que sugiere que estos clones son altamente resistentes al hongo.

Los 115 clones seleccionados se probaron serológicamente (ELISA) para ambos virus y se encontró que 69 (60.0\%) estaban sanos, 43 (37.3\%) eran positivos al PVX y $3(2.7 \%)$ positivos al PVY. Lo cual confirma el alto porcentaje de escapes de plántulas asintomáticas principalmente al PVX, indicando que La Selva no es un ambiente adecuado para hacer tamizados para virus, salvo que se mejoren las condiciones para el tamizado. 
Algunos clones evaluados por segunda vez en el campo para resistencia a $P$. infestans y que fueron portadores de PVX, eventualmente podrían presentar resistencia al hongo inducida por la presencia del virus, ya que Fernández de Cubillos (1975) y Pietkiewicz (1971) afirman que la presencia del PVX y otros virus en algunas variedades de papa, aumentan la resistencia a $P$. infestans, bajo condiciones de campo e invernadero. Esto en el caso del material proveniente del Plan B. En el caso del Plan A, la posibilidad de resistencia inducida es mínima, por cuanto el tamizado para virus fue bastante eficiente y el porcentaje de escape fue mínimo.

En la Tabla 1 se presentan los valores de los efectos de la hcg de los probadores (padres) para cada uno de los cuatro ambientes experimentales. Según los resultados obtenidos durante el tamizado en Tibaitatá, los mejores progenitores masculinos fueron BL-2.2 y el I-1039, combinados con la línea [(LT-8 x AVRDC-1287)3], mientras que los padres con menor aporte de resistencia fueron Tollocan y 575049. Cuando se tamizó bajo condiciones de tinglado en La Selva, Ios resultados de la hcg fueron totalmente opuestos al tamizado anterior, en este caso 575049 fue el mejor padre y presentó la mejor combinación con la línea [(LT-8 x C83-119)6], seguido del Bulk y Bl-2.9. Al evaluar la resistencia a $P$. infestans en el campo de las progenies tamizadas en el Plan A se encontró que la hcg varía considerablemente respecto al tamizado en invernadero; se encontró que 1-1039, 575049 y Tollocan fueron los mejores padres para aportar resistencia. Cuando se evaluó la resistencia en el campo de las progenies tamizadas bajo condiciones de tinglado (Plan B) se encontró que los mejores padres fueron BL-2.9 combinado con las líneas [(BZuraxLT-7)14] y [(LT-8 x 575049)8].

Un porcentaje más bajo de clones fue resistente al tizón tardío en tinglado, lo cual indica que en este ambiente el descarte fue más severo, sin embargo, se obtuvo un alto número de genotipos que no fueron resistentes bajo condiciones de campo. Sólo 21 y $28 \%$ de los genotipos resistentes en el invernadero y tinglado respectivamente fueron también resistentes en condiciones de campo en "La Selva" y con adaptación agronómica. No se detectaron padres con habilidad para transmitir resistencia a $P$. infestans en todos los ambientes probados. 
Tabla 1. Valores de los efectos de la habilidad combinatoria general de los probadores (padres) para cada uno de los cuatro ambientes experimentados.

\begin{tabular}{cccc}
\hline $\begin{array}{c}\text { Invernadero } \\
\text { Tibaitatá }\end{array}$ & $\begin{array}{c}\text { Campo } \\
\text { La Selva }\end{array}$ & $\begin{array}{c}\text { Tinglado } \\
\text { La Selva }\end{array}$ & $\begin{array}{c}\text { Campo } \\
\text { La Selva }\end{array}$ \\
\hline $8.00 \mathrm{a}$ & 8.09 & 5.80 & 5.56 \\
BL.2.2 & $\mathrm{I}-1039$ & 575049 & BL.2.9 \\
6.43 & 4.41 & 1.05 & 4.81 \\
I-1039 & 575049 & Bulk & Bulk \\
5.31 & 1.47 & -0.13 & 3.37 \\
BL.2.9 & Tollocan & BL.2.9 & BL.2.2 \\
1.37 & -0.71 & -0.38 & -1.50 \\
Bulk & Bulk & BL.2.2 & I-1039 \\
-1.50 & -2.65 & -0.82 & -2.12 \\
I-1035 & BL.2.9 & I-1035 & 575049 \\
-9.50 & -4.33 & -1.51 & -2.12 \\
575049 & BL.2.2 & Tollocan & I-1035 \\
-10.12 & -627 & -4.00 & -8.00 \\
Tollocan & I-1035 & I-1039 & Tollocan \\
\hline
\end{tabular}

Las correlaciones de las resistencias para $P$. infestans obtenidas bajo condiciones de invernadero, tinglado y campos (Tabla 2) fueron muy bajas y en ocasiones negativas, confirmando los resultados obtenidos por Stewart (1983), quien encontró poca correlación entre la resistencia obtenida en el invernadero con la de campo.

Tabla 2. Matriz de correlación de la resistencia obtenida en los ambientes experimentales.

\begin{tabular}{lccc}
\hline & Campo 1 & Tinglado & Campo 2 \\
& & & \\
\hline Invernadero & 0.053 & -0.138 & 0.055 \\
Campo 1 & & -0.054 & -0.012 \\
Tinglado & & & 0.021 \\
\hline
\end{tabular}




\section{Conclusiones}

1. El tamizado para virus bajo condiciones de Tibaitatá se considera adecuado, ya que el porcentaje de plántulas asintomáticas estuvo muy cerca de lo esperado.

2. Dadas las condiciones favorables para el desarrollo de $P$. infestans y la severidad con que se expresan los síntomas, se considera La Selva como un lugar apropiado para tamizar y evaluar progenies bajo condiciones de campo.

3. El tamizado para virus en La Selva, permitió un alto porcentaje de escape de plántulas portadoras, que sólo pudieron ser detectadas mediante serología (ELISA).

4. Con los tamizados para virus y tizón tardío y la evaluación de la resistencia de esta última en el campo, se obtuvo un alto porcentaje de clones inmunes a PVX y PVY, resistentes a $P$. infestans y con buenas características agronómicas.

5. Para el carácter resistencia a $P$. infestans no se detectaron padres con habilidad para transmitir uniformemente ese carácter a su progenie en todos los ambientes probados.

Dadas las condiciones en que se realizó la presente investigación y los resultados obtenidos, se sugieren algunas modificaciones con el fin de simplificar y hacer más eficiente el trabajo.

1. Caracterizar varios aislamientos de los virus PVX y PVY, con el fin de encontrar algunos que se expresen mejor en los hospedantes susceptibles.

2. Combinar algunos clones línea (inmunes) utilizados en este trabajo con material andigena, libre de genes mayores, con el fin de obtener en forma más fácil la resistencia de campo.

3. Chequear la inmunidad para PVX y PVY de los clones doblemente evaluados para $P$. infestans en el campo, con el fin de utilizarlos como parentales en el Programa de Mejoramiento o como clones avanzados.

\section{Referencias Bibliográficas}

1. Barrera, R.C.E. 1987. Seguimiento virológico de clones de papa con genes para resistencia a PVX y PVY bajo condiciones de campo. Tesis. Universidad Nacional Agraria La Molina. Lima, Perú. 78 p.

2. Bokx, J. A. de. 1980. Virosis de la papa y de la semilla de papa. Editorial 
Hemisferio Sur. S.A. Buenos Aires, Argentina. 303 p.

3. Centro Internacional de la Papa. 1979. Screening for resistance to PVX and PVY. Circular VII (1). Lima, Perú.

4. Fernández-Northcote, E.N. 1983. Prospects for stability of resistance to potato virus Y, P.82, En: W.J. Hooker Ed. Research for the potato in the year 2000. CIP. Lima, Perú. 199 p.

5. Fernández, C. de.; Thurston, H.D. 1975. The effect of viruses on infection by Phytophthora infestans (Mont) de Bary in potatoes. Am. Potato J. 52:221-26.

6. García, Ch. E.R. 1989. Estabilidad de la resistencia a PVX, PVY y PLRV en clones de papa expuestos al campo y áfidos asociados con la transmisión. Mg.Sc. Tesis. Universidad Nacional Agraria La Molina. Lima, Perú. 103 p.

7. Henfling, J. 1987. El tizón tardío de la papa. Boletín de Información Técnica 4. CIP. Lima, Perú. 24 p.

8. Hooker, W.J. 1980. Compendio de enfermedades de la papa. Traducido del Inglés por Teresa Ames de Icochea. CIP. Lima, Perú. 166p.

9. Muñoz, F.J.; Plaisted, R.L.; Thurston, H.D. 1975. Resistance to potato virus $Y$ in Solanum tuberosum ssp. andigena. Am. Potato J. 52:107-115.

10. Pietkiewicz, J. 1974. Effect of viruses on the reaction of potato to $P$. infestans I. Characteristic of reaction to $P$. infestans of plañís infected with potato viruses $\mathrm{X}, \mathrm{Y}, \mathrm{S}, \mathrm{M}$ and leaf roll. Phytopath. Z. 81:364-72.

11. Ross, H. 1986. Potato Breeding-Problems and Perspectives. Verlag Paul Parey. Berlín and Hamburg. 132 p.

12. Singh, R.K.; Chaudhary, B.D. 1977. Biometrical Methods Quantitative Genetic Analysis. Kakyani Publishers. N. Delhi. 304 p.

13. Stewart, J.E.; Flavelle, P.H.; Me Calmont, D.C.; Wastic, R.L.. 1983. Correlation between glasshouse and tests for resistance to foliage blight by P. infestans. Potato Res. 26:41 -48. 